\title{
COMBINING A VIRTUAL LEARNING TOOL AND ONSITE STUDY VISITS OF FOUR CONSERVATION SITES IN EUROPE
}

\author{
A. CHENAUX ${ }^{1}$, M. MURPHY ${ }^{1}$, G. KEENAGHAN ${ }^{1}$, J. JENKINS ${ }^{3}$, \\ E. McGOVERN ${ }^{1}$, S. PAVIA ${ }^{2}$ \\ ${ }^{1}$ Dublin Institute of Technology, Ireland \\ ${ }^{2}$ Trinity College Dublin, Ireland \\ ${ }^{3}$ Purdue University, USA \\ Alain.Chenaux@dit.ie, Maurice.Murphy@dit.ie
}

Keywords 3-D Modeling, visualization of cultural heritage, Virtual Learning Environment, HBIM

\begin{abstract}
The design and evaluation of virtual learning environments for construction and surveying students is presented in this paper; by combining virtual learning environment and on-site student surveys to model and replicate practice in the architectural heritage sector. The Virtual Learning Environment is enhanced with real live survey projects whereby students collect the data to build virtual historic buildings from onsite surveys using advanced survey equipment. The survey data is modelled in HBIM; Historic Building Information Modelling (HBIM) is currently being developed as a virtual learning tool for construction and surveying students in the Dublin Institute of Technology. HBIM, is a novel solution whereby interactive parametric objects representing architectural elements are constructed from historic data, these elements, including detail behind the scan surface are accurately mapped onto a laser or image based survey. The architectural elements are scripted using a Geometric Descriptive Language GDL. In the case of this project a Virtual Learning Environment is being developed which combines advanced recording and surveying with Building Information Modelling (BIM) to simulate and analyse existing buildings.
\end{abstract}

\section{INTRODUCTION}

The aim of this paper is to present the outcome of four study visits of Dublin Institute of Technology and Purdue students to four conservation sites in Europe: Leaning tower of Pisa, National Monument Edinburgh, Karolinum university building of Prague, Henrietta Street Dublin and the subsequent development of a Virtual Learning Environment using both the survey data and Building Information Models (BIM). Every year students from the Dublin Institute of Technology in Ireland carry out a survey of a historic building in Europe. The aim of the survey is to introduce students to the principles of building conservation in other EU states. The onsite surveys and reference to existing survey data, also give the students an insight into restoration techniques and the methods of construction used in these buildings over their lifespan. The modelling system described as Historic Building Information Modelling (HBIM) [1,2,3] is a novel prototype library of parametric objects based on historic data and a system of cross platform programmes for mapping parametric objects onto a point cloud and image survey data. The HBIM process begins with remote collection of survey data using a terrestrial laser scanner combined with digital photo modelling. The next stage involves the design and construction of a parametric library of objects, which are based on the manuscripts ranging from Vitruvius to 18th century architectural pattern books [4]. In building parametric objects, the problem of file format and exchange of data has been overcome within the BIM ArchiCAD software platform by using geometric descriptive language (GDL). The plotting of parametric objects onto the laser scan or other surveys as building components to create or form the entire building is the final stage in the reverse engineering process. The final HBIM product is the creation of full 3D models including detail behind the object's surface concerning its methods of construction and material make-up. The resultant HBIM can automatically create cut sections, details and schedules in addition to the orthographic projections and 3D models (wire frame or textured). In the case of this project, a novel aspect is introduced through applying both traditional and advanced recording and building modelling techniques developed in the Dublin Institute of Technology to develop a Virtual Learning Environment to simulate and analyse historic buildings. The four surveys are described in this paper detailing the methods of on-site and off-site data collection and the process of building partial models of the buildings. In conclusion a theorethical design framework is described for combining the onsite surveys and the Historic Building Information Modelling to create a Virtual Learning Environment which has the potential to expand and be shared by other educational institutes. 


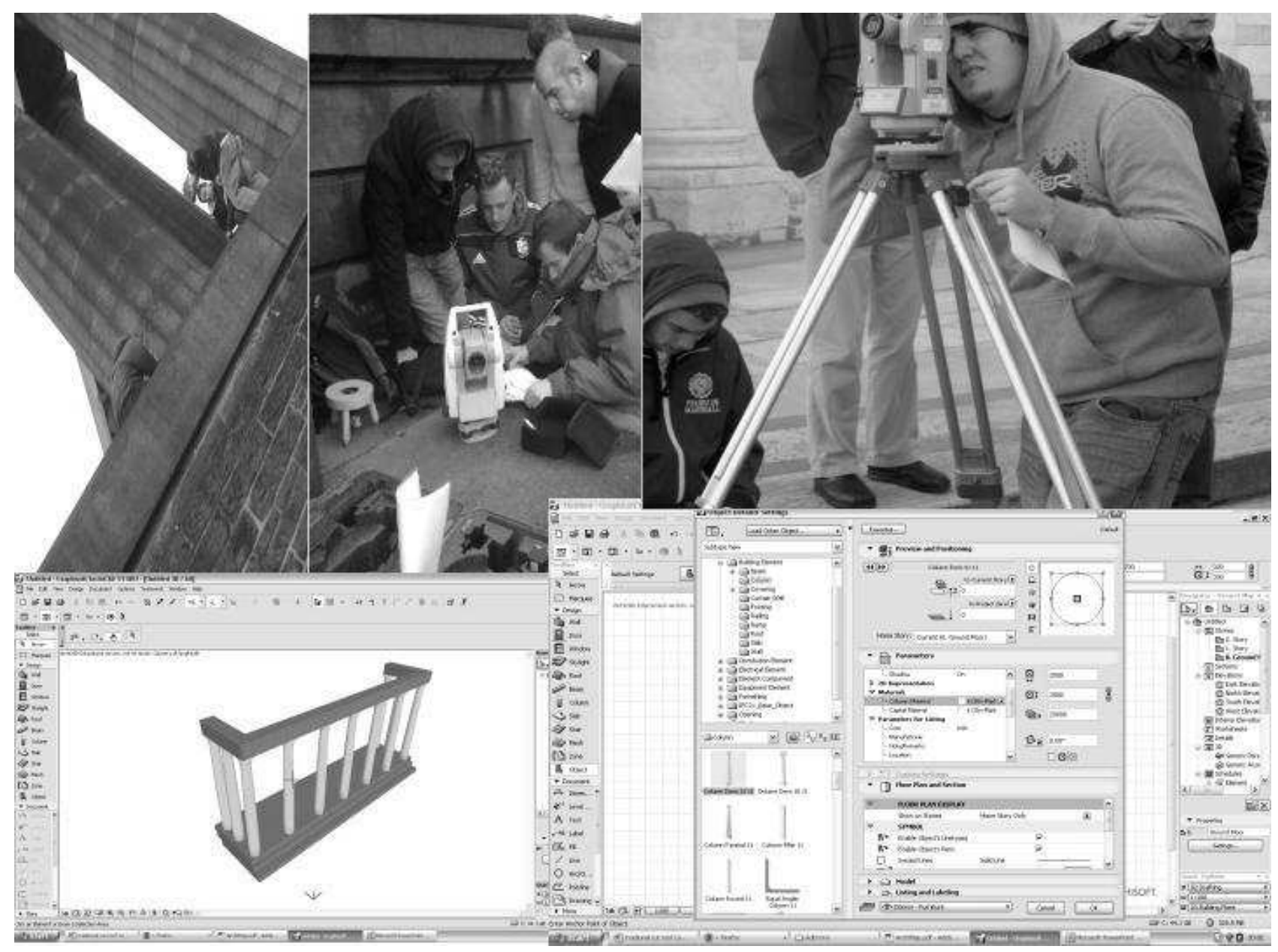

Figure 10: Students on-site surveying and HBIM model

\section{SURVEY: LEANING TOWER OF PISA}

The HBIM process in this case was divided into three steps: The first was based on existing laser-scan survey data and 2D digital photo-modelling; the second based on ground truth survey data collection using theodolites and hand-held laser measurement units (distometers) and finally stage three, the creation of Historic Building Information Model of the tower [5].

\subsection{Step 1- existing survey data photographic and laser survey of the building}

The identification of building typology, architectural detail, geometry, principles of the external and internal structure and fabric, positioning of openings, proportional relationship of the building's elements and classical detailing were initially based on existing laser scans, photographies and CAD surveys of the historic structures downloadable from the website of CyArk, a non-profit entity (http://archive.cyark.org/). CyArk's mission is to digitally preserve cultural heritage sites through collecting, archiving and providing open access to data created by laser scanning, digital modeling, and other state-of-the-art technologies. The CyArk's database allowed the students to access information such as the data detailed in Figure 2. The product of the laser scan survey is described as a point cloud, which represents the $\mathrm{x}, \mathrm{y}, \mathrm{z}$ coordinates of a scanned object (Figure 2). The point cloud can then be textured from image data to create a virtual 3D model of a structure or object; accurate measurements can be abstracted from the point cloud. Existing 2D $\mathrm{CAD}$ drawings and historic surveys as detailed in Figure 3 were also used to obtain measurements of the structure. 


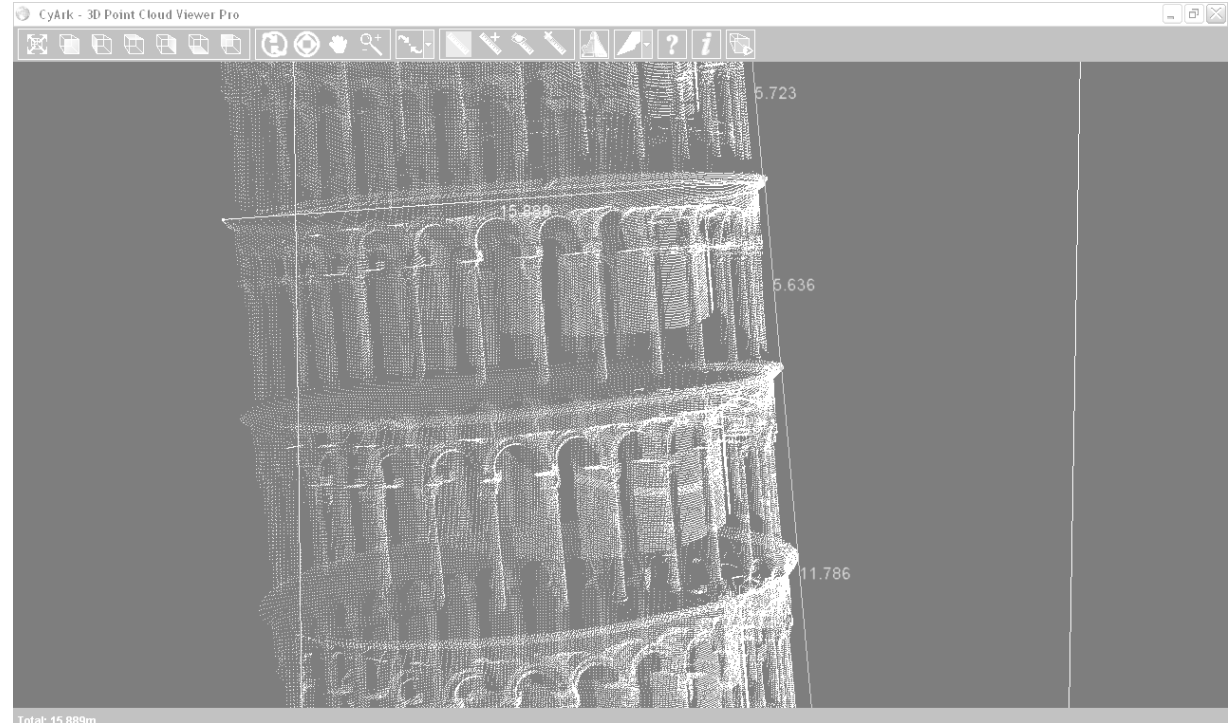

Figure 11: Laser Scan Survey of the Leaning tower of Pisa

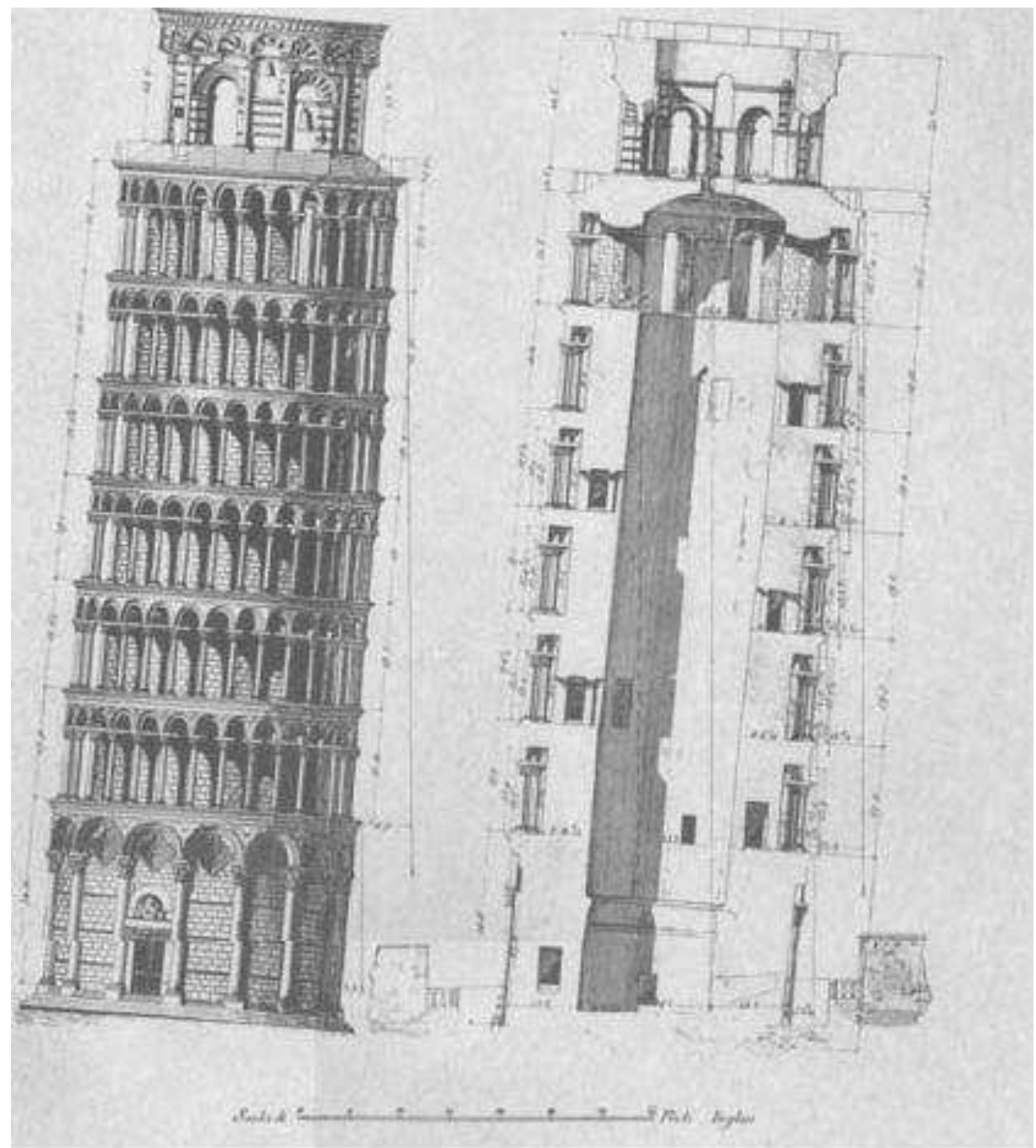

Figure 12: Historic Survey Data 
Digital photography was used for 2D/3D modelling and independent data collection. The 2D modelling was achieved through taking accurate ground truth survey measurements on the object and geo-referencing the images using target measurements on the image representing $\mathrm{x}$ and $\mathrm{y}$ coordinates at a minimum of four points as detailed in Figure 4.

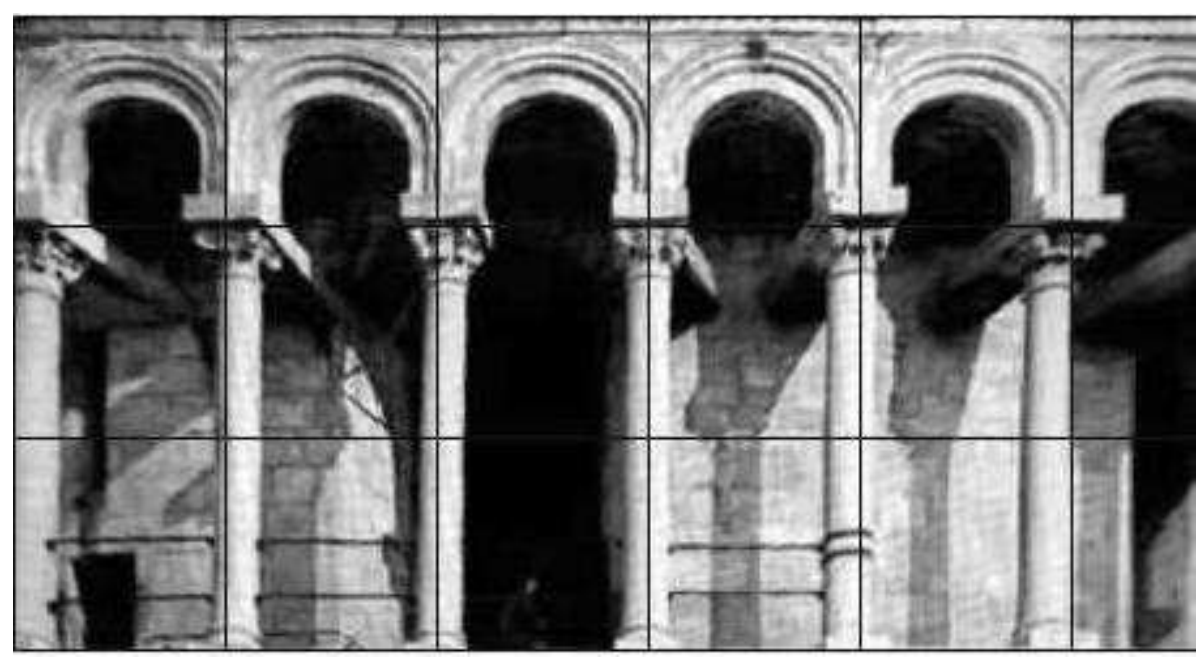

Figure 13: Geo-referenced Image of Tower Section

\subsection{Stage 2- collection ground truth survey data using theodolite and hand held laser}

A traditional surveying approach was taken involving the use of 10" theodolites to record angles in both the horizontal and vertical planes and laser distometers to obtain distances. A framework of control stations was first established around the tower of Pisa. When deciding upon the station locations common surveying rules were respected including intervisibility between stations, the formation of a well-conditioned control framework and checking that each point of interest could be visible from at least two stations [6].

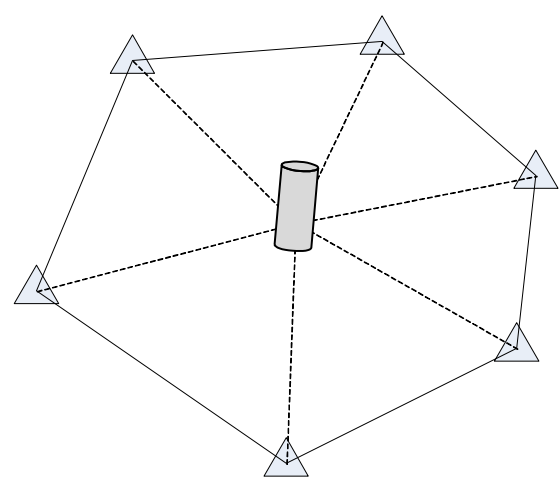

Figure 5: Control framework

Horizontal and vertical angles as well as distances were recorded between survey stations and coordinates were calculated in an arbitrary coordinate system based on the traverse calculations. A fractional linear misclosure better than 1:10’000 was computed which would be within the allowable range for large construction projects [7]. The intersection method was then applied to determine the relative position of detail points on the tower once both horizontal and vertical angles were observed with the theodolite. Each detail point $\mathrm{P}$ was observed from two separate stations and both horizontal and vertical angles were recorded (Figures 6 and 7). As a check both faces were considered allowing for a 1' error. Once all the data was recorded students created their own functions within Excel to compute the relative position of all points observed (Figures 6 and 7). Since the vertical angle of each detail point was observed from two different control stations the height can be computed for each of the two instrument positions A and B. A consistent difference of a few centimetres was present between two measurements of the same height coordinate. 


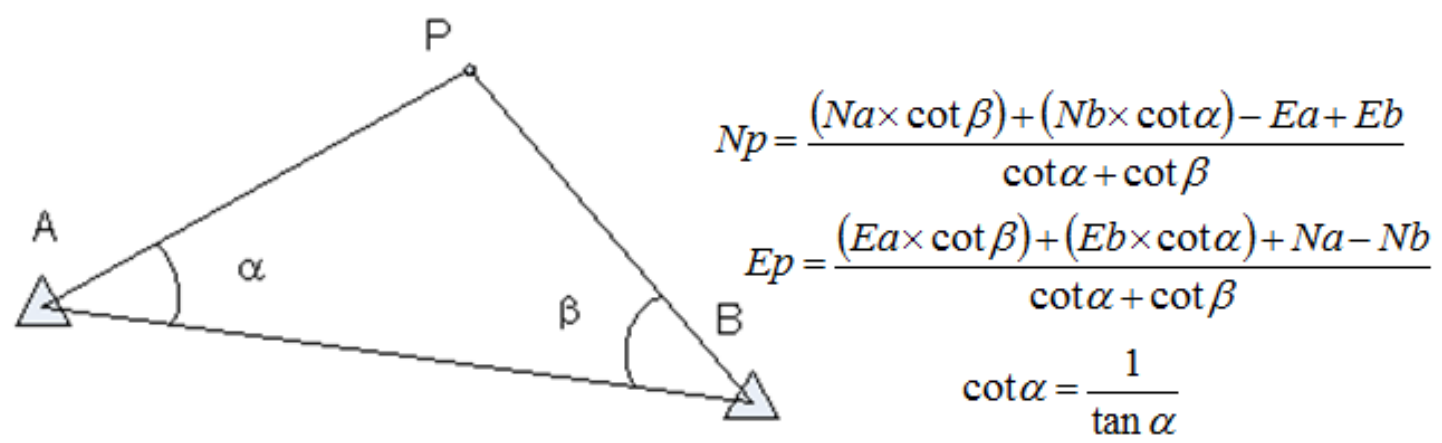

Figure 14: Intersection method in the horizontal plane and equations used to compute $\mathrm{X}, \mathrm{Y}$ coordinates

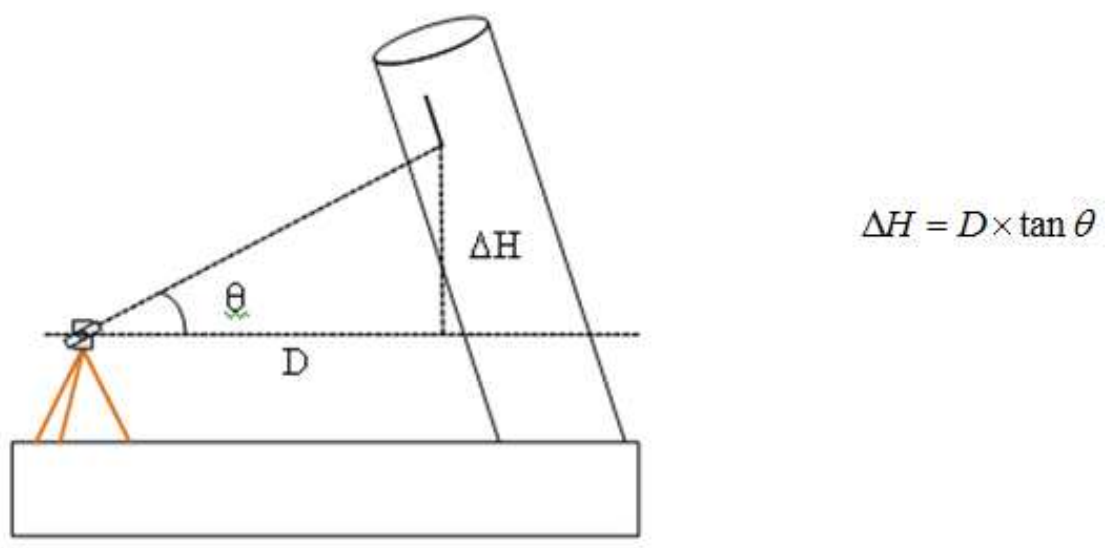

Figure 15: Equation used to compute $\mathrm{Z}$ coordinate

The geometry outline of some decayed features proved to be challenging when deciding upon detail points to be recorded with the instruments. In this regard, laser distometers were utilised for recording distances for important architectural features where accessibility was a problem.

\subsection{Pisa Building a Partial Model of the}

Data from the on-site survey, ortho-images, and laser scan data were used to obtain the measurements for this model and were plotted in a 3D CAD environment. A circle was constructed based on the diameter of the tower (15.484M), from this a pendedecgon (a 15-sided, 15-angled, polygon) was positioned to represent the positions of the 15 columns on the base level (see detail a Figure 8). Once the pendedecgon was completed, the base of the column was constructed first in 2D and then in 3D (see detail b). A similar process was used for the capitol of the column, initially in 2D, and then primitive shapes were positioned to construct the 3D model of the capitol (detail c). Next, the capitol and base were positioned and the shaft of the column was drawn with a cylinder to create the full the 3D Model of the column (detail d). For the construction of the arch a Boolean operation combined a half cylinder which was subtracted from a solid cuboid to replicate the arch (detail e). When the objects were constructed, the positioning of each element was located using the pendedecgon to position the object, the function ARRAY was used to position the 14 other columns on their correct locations. Similarly, the arch block was positioned on top of two columns and was once again arrayed to fill the entire area symmetrically, resulting in the final model illustrated in detail $\mathrm{f}$. and $\mathrm{g}$. It must be noted that the objects used to plot the 3D model (see detail g) are not parametric, the concept of using parametric objects are introduced in the building of the next three models. 

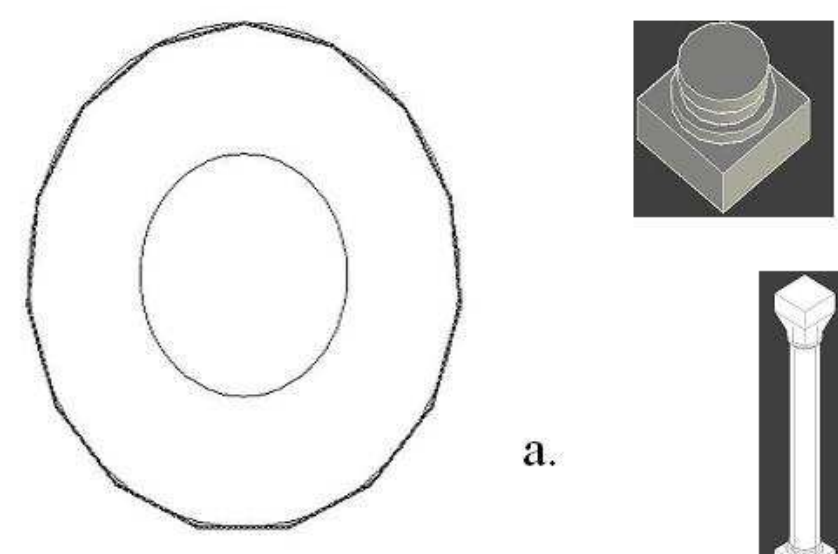

b.

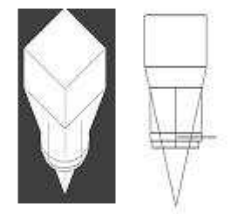

C.

a.
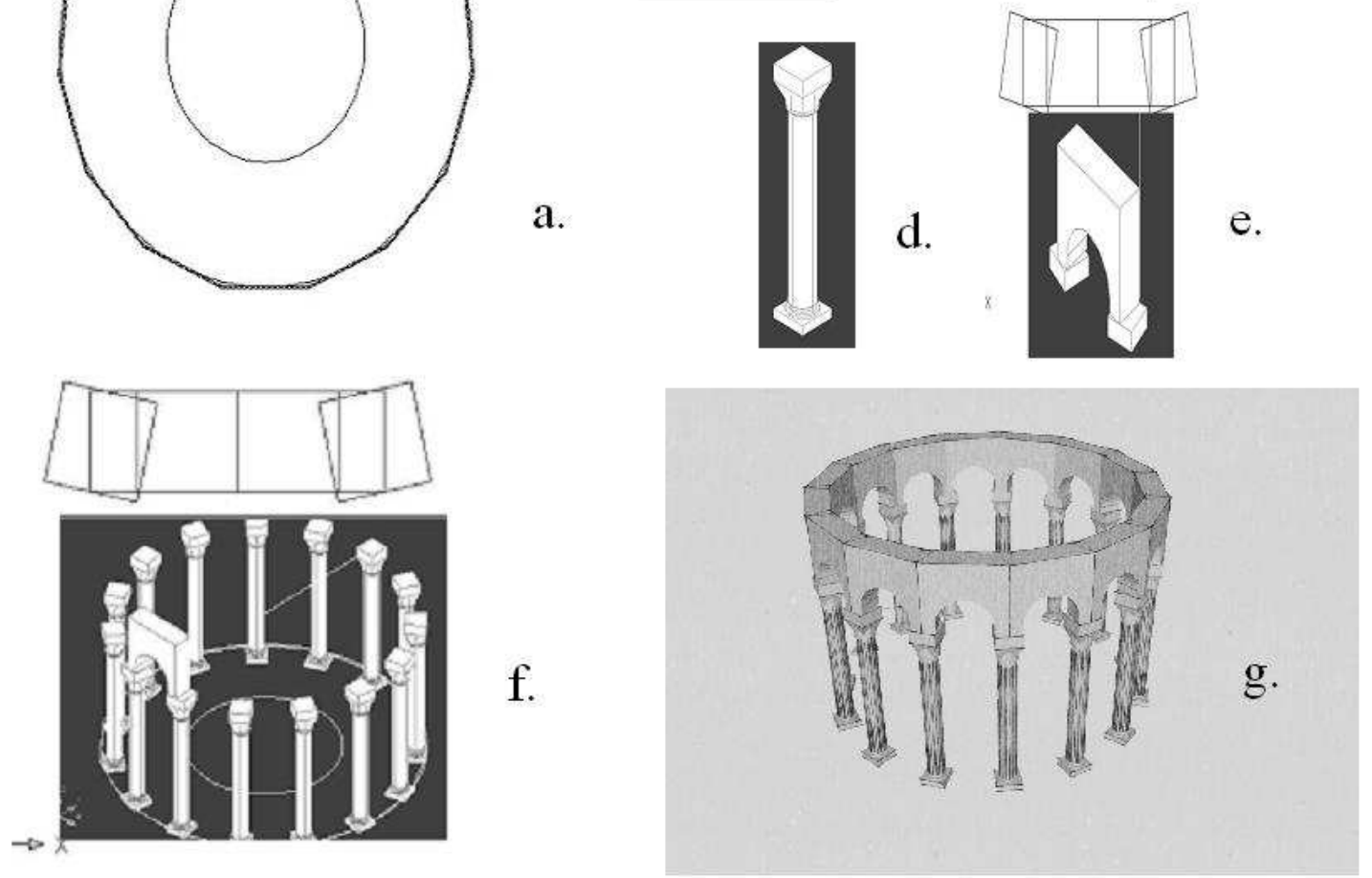

Figure 16: HBIM of base of Pisa Tower

\section{SURVEY: NATIONAL MONUMENT EDINBURGH}

The second study is a survey of the National Monument constructed in 1826. It is located in Edinburgh and is a Napoleonic war memorial, which is partially modelled on the Parthenon in Athens. The students were required to carry out a survey of the elevation of the building using total station, laser and image techniques, producing a full set of $3 \mathrm{~d}$ drawings. Initially historic research and background which included identified building typology and architectural documents which detail: geometry and principles of the external and internal structure and fabric construction; positioning of openings; proportional relationship of the building's elements; and classical detailing. A Leica TS1205 reflectorless total station and digital photography was used for 2D/3D modelling and independent data was collected using laser hand held measurements on the object and rectifying the images to scale using target measurements on the building. When recording data with the total station an arbitrary coordinate system was created from a baseline running between two control stations. The coordinates of all visible detail points were recorded from the first control and stored in the instrument's internal data logger. The use of a second control station allowed for recording points, which were either obstructed or poorly visible from the first station. When detail points were recorded from both stations their initial coordinates from the first station were compared with the coordinates from the second station. Differences in the horizontal plane were in the order of $10 \mathrm{~mm}$ and $20 \mathrm{~mm}$ in the vertical plane. The 3D modelling of objects and extraction of measurement data was based on the use of Google Sketch-up and ArchiCAD Building Information Modelling software platforms. In Figure 9, the terrain model was constructed using Google Sketch-up, a. and b. detail the solid construction and meshing process using triangles, the terrain is modelled in $\mathrm{c}$. and the model is put in place in e. 

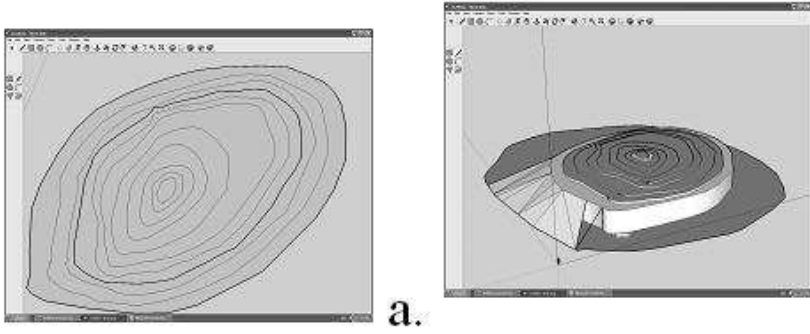

b.

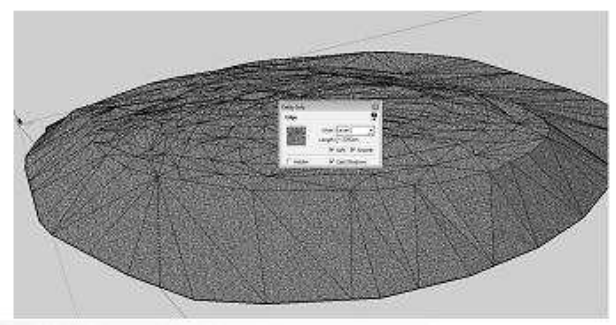

c.

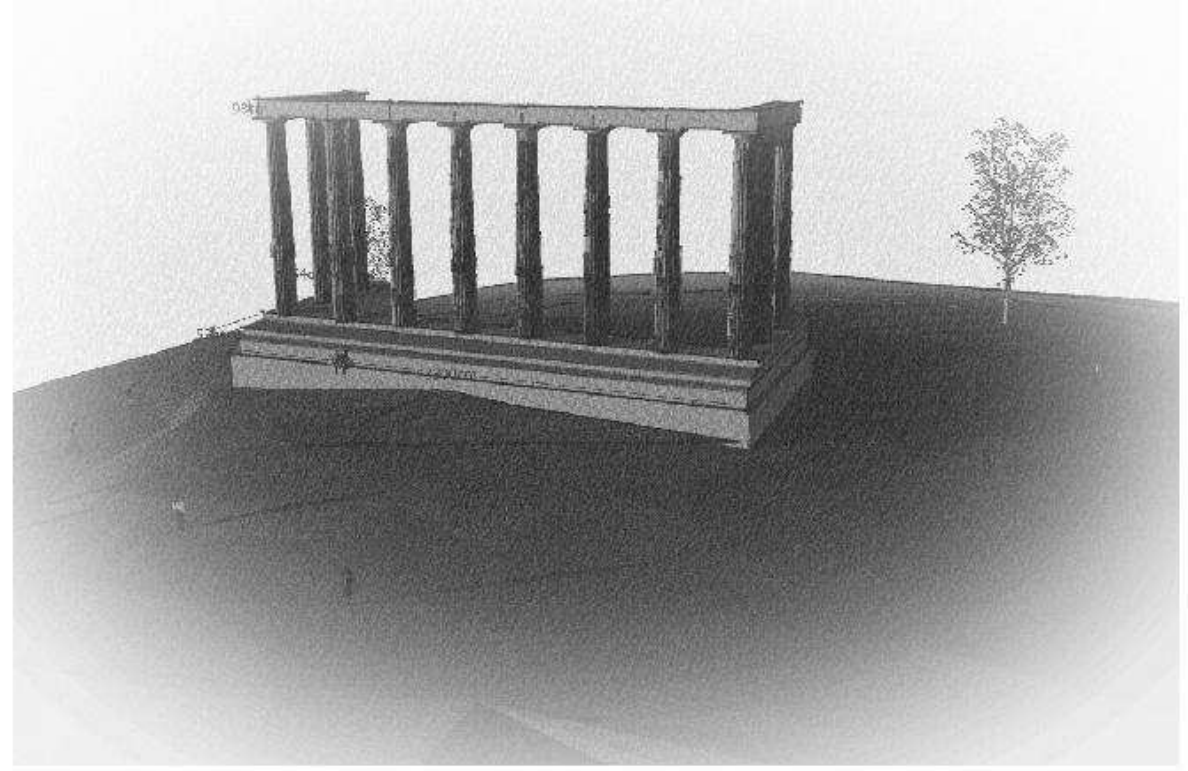

e.

Figure 17: HBIM of National Monument

The process for constructing the 3D BIM model is detailed in Figure 10. The $\mathrm{x}, \mathrm{y}$ and $\mathrm{z}$ co-ordinates are transferred to data sheets which represent the geometry of the objects which make up the entire model. Mapping objects based on survey data can overcome the slow task of plotting and locating every vector to represent the 3D object. As parametric objects there is an opportunity to introduce details behind the object's surface concerning its methods of construction and material make-up. Within Historic Building Information Modelling, the library of parametric objects exists in libraries or has to be constructed by editing existing objects or scripting them using geometric descriptive language. When a library part or parametric object is placed into the HBIM, it is placed as an icon in 2D in the floor plan position (separated by height or formation levels) as detailed in a. and determined along the $\mathrm{x}, \mathrm{y}$-axis and in section and in elevation, on the z-axis. The library objects are not plotted directly in $3 \mathrm{D}$ environments, with the result that the objects are not lifted and placed within the 3D point cloud. The survey data can supply floor plans, whereas rectified images can detail elevations and sectional cuts as a map for location of library objects. Further interrogation of survey data supplies numeric values for formation values (for $\mathrm{z}$-axis location) and parametric values for the library objects themselves, these are recorded in data sheets. Objects are also positioned onto the orthographic image in elevation and adjusted in side elevation and section for angular displacement. In Figure 10, part of the process for mapping objects total station and image-based surveys is illustrated. The position of the slabs are detailed in a. and shown in 3 dimensions in b. The Doric columns are chosen from library parts in c. and placed in floor plan in d. Finally e. and f. illustrate the completed 3D HBIM model. 


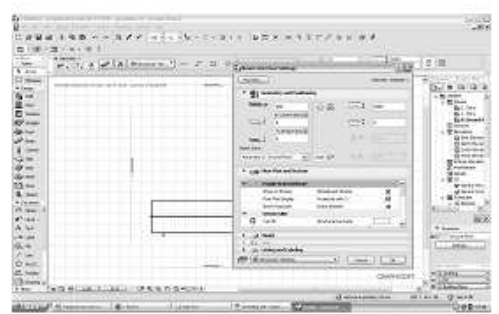

a.

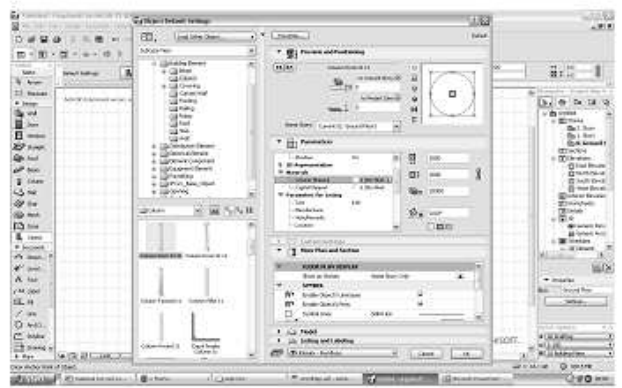

c.

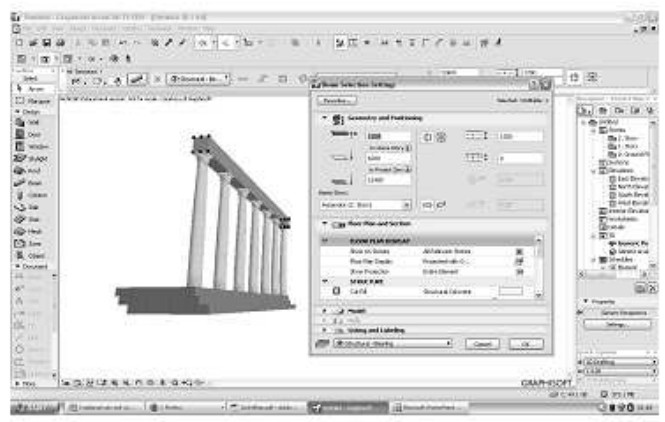

e.

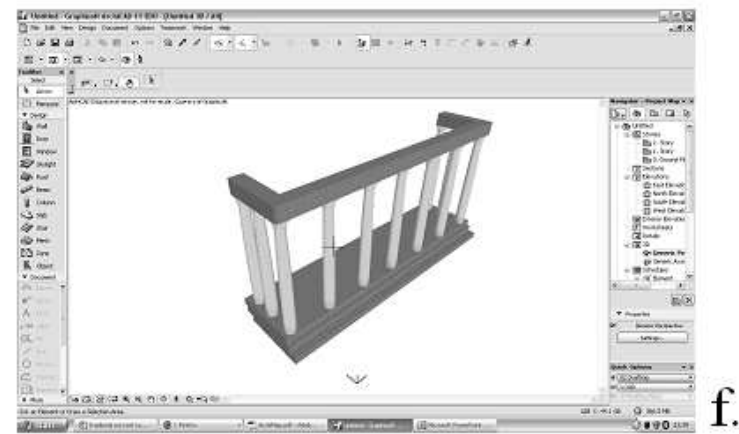

Figure 18: HBIM process

\section{SURVEY: KAROLINUM PRAGUE}

Charles University was founded in 1348 by King Charles IV and is believed to be the oldest university in Central Europe. Wenceslas IV bought a site containing a few houses which were rebuilt for the university and renamed the site Karolinum. Pre-university Gothic structures include the Chapel of Saint Cosmas \& Damian and an oriel window protruding from the southern wall (also visible in Figure 11). The complex went through different architectural epochs during its existence; in the early 18th century it was rebuilt in baroque style then in the late 19th century some parts were rebuilt in Neo-Gothic style. The adjacent red brick building was considered for the HBIM model. As with the the National Monument in Edinburgh the coordinates were directly obtained and recorded using a Leica TSR1205 reflectorless total station. A baseline was setup along two control stations from which an arbitrary coordinate system was chosen. All detail points were recorded from at least one control station (Figure 11). When no obstruction occured detail points were observed from both stations and compared. A typical error of less than $10 \mathrm{~mm}$ and $20 \mathrm{~mm}$ in the horizontal and vertical plan respectively occurred. However the restricted working space for positioning in potential control station locations around the Karolinum building resulted in a poor geometry when recording building detail at higher elevation and this greatly affected the accuracy. 

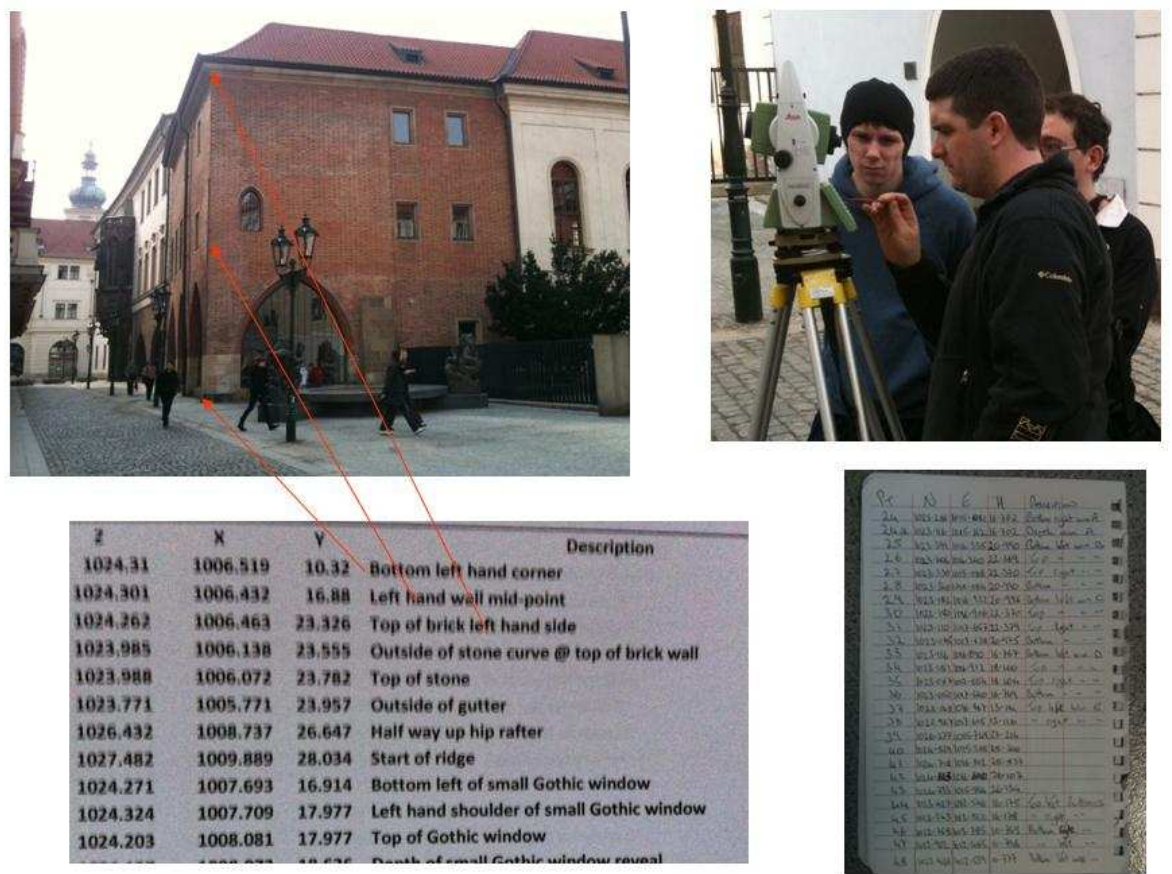

Figure 19: Building being surveyed from the first control station [8]

Below is the HBIM model based on the survey data and built with a similar methodology to the National monument Edinburgh, a. represents the front view of the building, b. is an isometric view, c. d. and e. represent 3D cuts for analysis of the building. Sections of the building are represented in details $g$ and $h$ and finally details $f$ and $i$ represent 3D elements from the building.

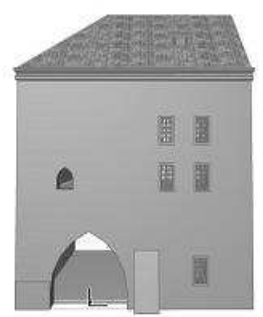

a.

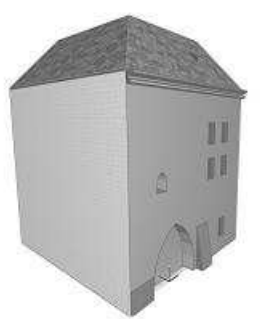

b.
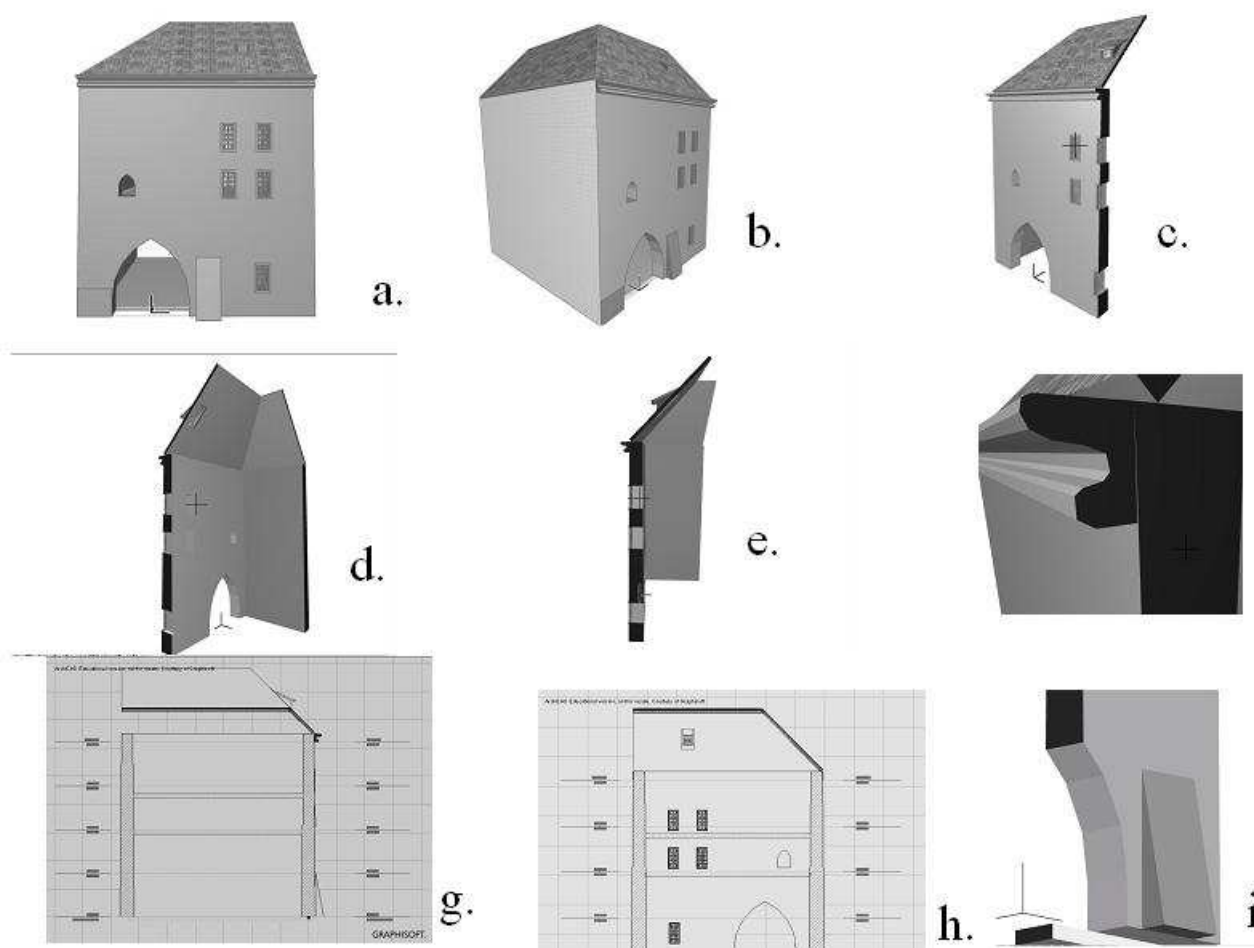

f.
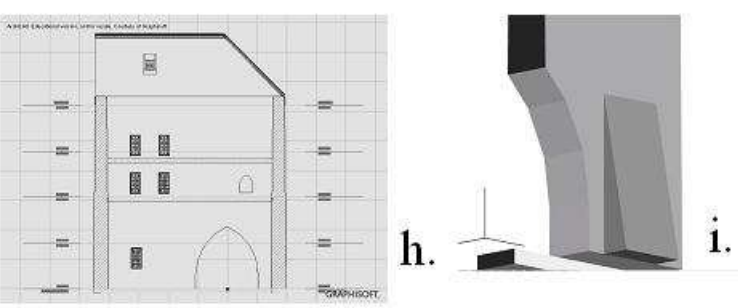

Figure 11: HBIM of Karolinum building 


\section{SURVEY: HENRIETTA STREET DUBLIN}

As the first step in extending the project of recording European historic structures, in May 2010, a group of North American Purdue University students were introduced to the current conservation project, laser scan surveying and HBIM of Henrietta Street. This is one of Dublin's earliest Georgian streets and is still intact, the street was constructed between 1730 and 1820. A survey was conducted to gauge student perception of Henrietta Street in regard to its history and of the recent renovation project. The students responded that they were very impressed with the detailed planning, care, and patience taken to correct the structural problems with minimal disruption to the interior finishes of the building. Students also stated that there was a lot of value in renovating Henrietta Street, which represents some of the oldest existing Georgian architecture in Dublin. For the Purdue students Henrietta Street offers a learning environment for understanding historic preservation, the next stage of this collaborative project with Purdue is the use of the HBIM models for remote student learning in their university environment. In Figure 13 the HBIM process of the facades of one of the buildings is illustrated starting with the laser scan of the buildings façade and the 3D model and automated drawings.
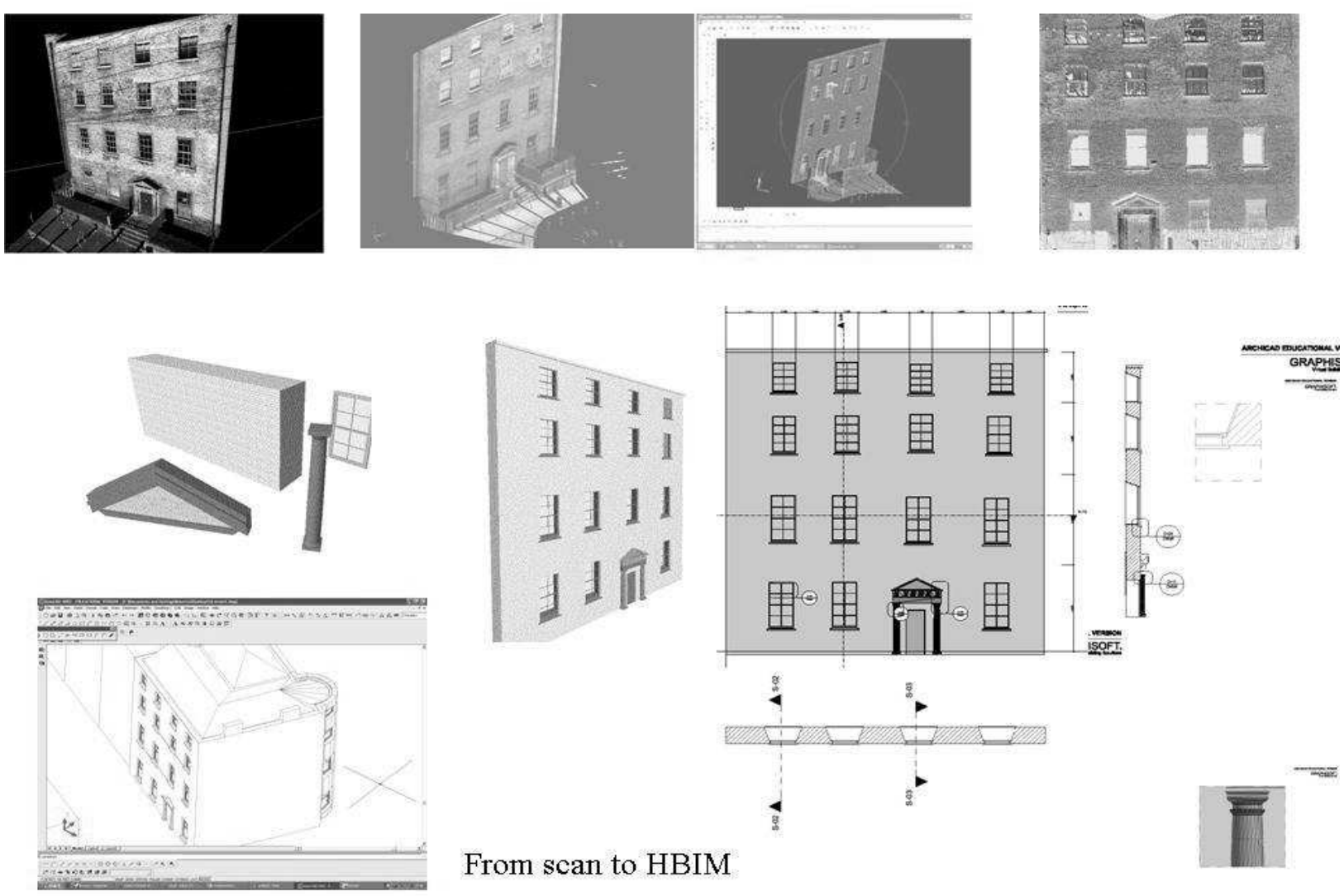

From scan to HBIM

Figure 12: HBIM Process Henrietta Street

\section{CONCLUSION - THEORETICAL DESIGN FRAMEWORK FOR A VIRTUAL LEARNING ENVIRONMENT}

Teaching and training architectural, engineering, construction and surveying students using computer simulations of buildings although recently developed is not new. In the case of this project a Virtual Learning environment is being developed which combines advanced recording and surveying with Building Information Modelling (BIM) to simulate and analyse existing buildings. In summary this learning software uses a purpose built plug-in library of parametric objects representing intelligent building components which are plotted within a virtual learning environment by the student onto a geometric framework based on laser or image surveys. The library of parametric objects contain the real world geometry, texture and specifications of building parts allowing the student to virtually analyse and experience 
different forms of architecture and structures. The parametric library parts are scripted using Geometric Descriptive Language (GDL), which is an open scriptable language. GDL is an embedded programming language in ArchiCAD (a Building Information Modelling Software Platform), which provides access to create and model parametric objects [9]. If Building Information Modelling (BIM) is incorporated into the design of Virtual learning, it offers a very different experience from classroom-based learning. When interacting online individual students have their own perspective and experiences whereby they construct their own interpretations of the knowledge [10]. This was exploited in the design of learning software; students will be encouraged to construct their own interpretation from the simulation of realistic scenarios of historic construction process thus improving the learning outcomes. In the case of this project the objective is to create a Web based learning software platform accessible from desktop personal computers, laptops and hand held devices, to enable individual and group based student learning. The learning software will simulate realistic case study scenarios based on site surveys of the historic construction process (how historic buildings are designed and constructed), thus bringing the real world into a virtual classroom. The learning software will be developed on the principals of instructional design, which focuses on the conditions in which learning will occur, and the principles of how people learn. A study in the Civil and Environmental Department at Worcester Polytechnic Institute confirmed that the use of BIM facilitated effective learning mainly because it involves sharing, communicating, and group problem solving. It also helps students to actively engage in the process of planning, designing, and interpreting construction related data. Moreover, the concept represents an invaluable tool to teach students the notion of cooperative work [11]. Developing a Web based learning platform using virtual models integrates technology into learning, promotes active learning, and develops an affective module [12]. The learning software will be developed to ensure the VLE is created as a means of educating the students and regular evaluation of the module delivery will ensure the learning software does not become just another mode of lecturer delivery. The number of technology tools (HBIM, Laser Scanning) being applied in various contexts will help to ensure the VLE is an active system of education [13]. The integration of both learning Web based technology and HBIM is a new and innovative aspect in the field of virtual and computer based learning.

There are three levels in the design of the Virtual Learning environment:

Level 1 - this is an introduction to the HBIM platforms using Google Sketch-up and ArchiCAD software platforms. Initial self-assessment identifies at what level a student should access the learning environment; this is built into tutorials to encourage the student to assess their entry level and encourage the student to revise and self-assess their work prior to moving to higher levels in the software. Figure 14, below is a sample of students work using Google Sketch-up.

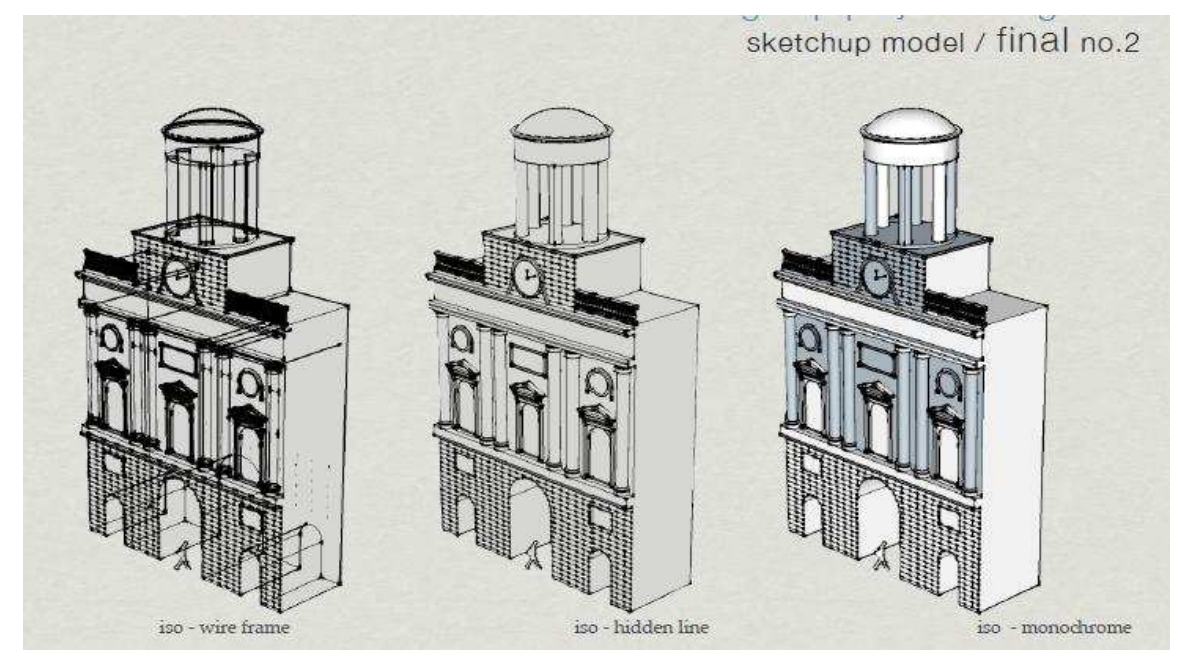

Figure 13: A sample of students work

Level 2 - Students are introduced to the library of architectural elements and how to build and script these objects using Geometric Descriptive Language (GDL), which is an open scriptable language that can be used to create parametric objects. GDL is an embedded programming language in ArchiCAD, which provides access to create and model parametric objects. The parametric objects are the components that the student brings together to form the entire building within a virtual environment. Figure 15 describes an example of a GDL script to form a Doric column. 


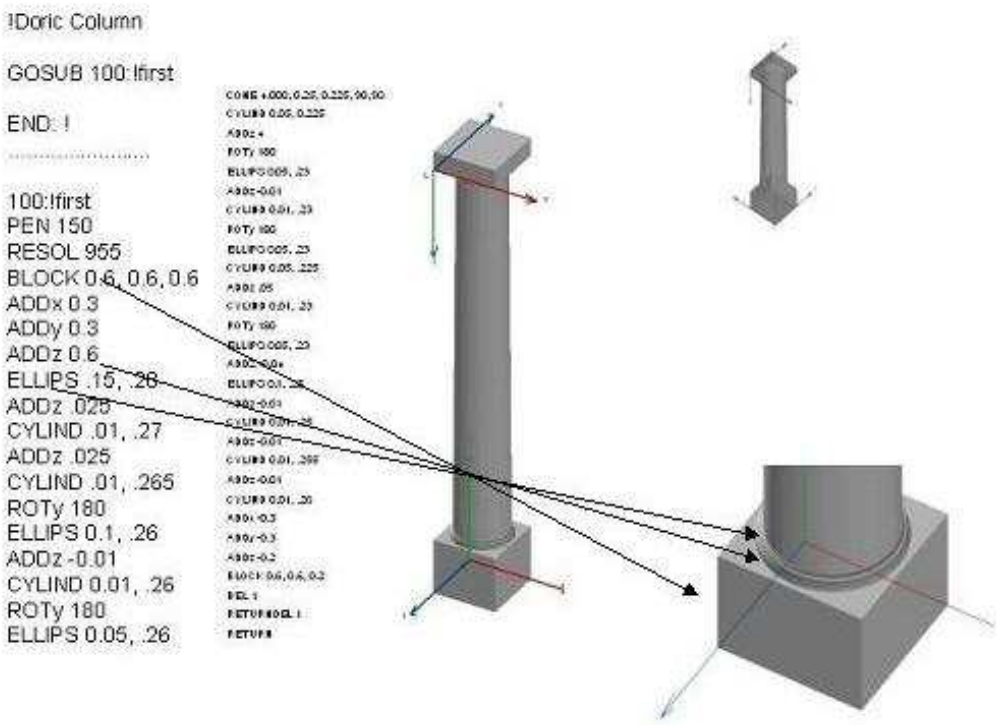

Figure 14: GDL Scripting

Level 3 - The students are introduces to the principles of building historic building information models based on the live site survey data and information sharing is introduced using student teacher WEB-based interaction inside the Virtual Learning Environment [14]. Student teacher WEB-based interaction inside the Virtual Learning Environment using ArchiCAD BIM Server ${ }^{\mathrm{TM}}$ allows student and teacher to collaborate in real-time on BIM models through standard Internet connections from virtually any location. The BIM models are located on a single server and accessed by the student and can be observed and assessed by the teacher as the students work through the virtual building. The learning software and virtual building models can be accessed by the student on the Internet through PC, laptop and hand held devices allowing participation and support for traditional and non-traditional learners.

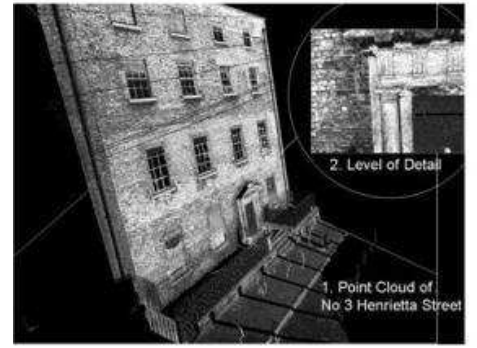

Use existing scans

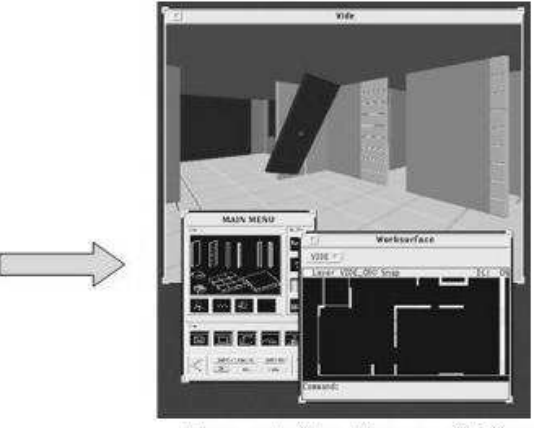

Use existing library of interactive Building components

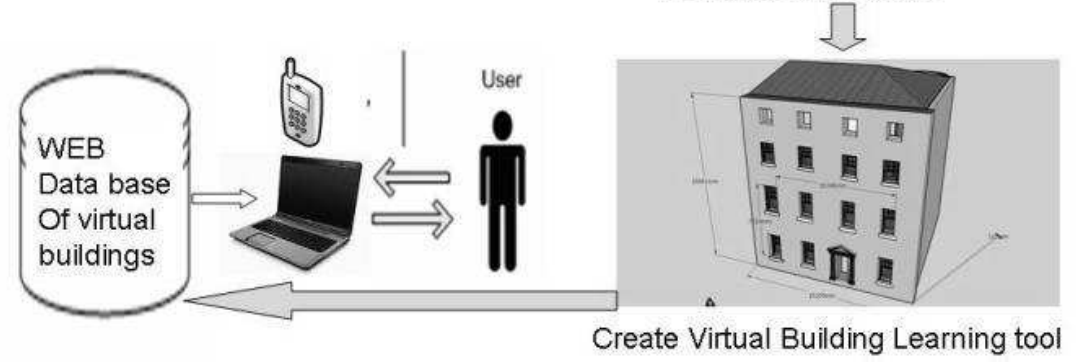

Figure 15: WEB Interaction 
In conclusion, the initial testing of the new concept of HBIM based virtual learning was evaluated through examining the students experience in using both the process and the software in creating the Historic Building Information Model (HBIM). The evaluation process was conducted through interview and presentation carried out by each student. The students did experience the full HBIM process, their reaction to each stage of the process differed; in stage one the students worked off virtual documents and had not as yet visited the site and this affected their enthusiasm and the accuracy of their work. The second stage where the students visited the site resulted in raised student motivation in carrying out the on-site survey, as this was a real experience for them to visit the site. Finally, in the creation of the HBIM models, the students found the software platforms were not totally compatible (from point cloud and survey data to 3D HBIM). In addition, the building of the library objects in GDL tended to be beyond the scope of the students. All of these learning constraints identified by the students are now informing a redesign of the HBIM virtual learning tool as part of the ongoing development. These modifications are been paralleled by research into the possibilities of including automated assessment in the HBIM virtual learning tool. It is proposed to extent this project to other third level institutes and to explore a joint European and North America funded project.

\section{REFERENCES}

[1] Murphy, M., et al.: Historic building information modelling (HBIM), STRUCTURAL SURVEY, Journal of Building Pathology 2009, VOL 27; NUMBER 4, 311-327, Emerald Group Publishing Limited.

[2] Murphy, M., et al.: Correlation of Laser-Scan Surveys of Irish Classical Architecture with Historic Documentation from Architectural Pattern Books, The VII international, interdisciplinary Nexus conference for architecture and mathematics San Diego, California, USA, June 2008.

[3] Murphy, M., et al.: The Processing of Laser Scan Data for the Analysis of Historic Structures in Ireland. In: Eds. Ioannides, M., Arnold, D., Niccolucci, F. and Mania, K. 37th CIPA International Workshop dedicated on e-Documentation and Standardisation in Cultural Heritage and 7th VAST International Symposium on Virtual Reality, Archaeology and Cultural Heritage. Nicosia, Cyprus, $30^{\text {th }}$ Oct $-4^{\text {th }}$ November 2006, 135- 139.

[4] Murphy, M., et al.: Parametric Vector Modelling of Laser and Image Surveys of 17th Century Classical Architecture in Dublin. In D. Arnold, F. Niccolucci, A. Chalmers (Editors), VAST 2007: The 8th International Symposium on Virtual Reality, Archaeology and Cultural Heritage Nov. 27 - 29, 2007, Brighton, UK.

[5] Murphy, M., et al.: An Evaluation Case Study - a Historic Building Information Model (HBIM) of the Leaning Tower of Pisa, ICERI 2009 Conference Programme, Edited by International Association of Technology, Education and Development, IATED, Madrid, 2009.

[6] Irvine, W. H., McLennan, F.: Surveying for Construction, McGraw Hill Education Co., 2006.

[7] Uren, J., Price, WF.: Surveying for Engineers, Fifth Edition, Palgrave Macmillan, 2010.

[8] Kelly, A., et al.: HBIM of Karolinum (Prague), DIT Module Project, Dublin Institute of Technology, 2011.

[9] Murphy, M., et al.: A Flexible Web Based Learning Tool For Construction and Surveying Students using Building Information Modeling and Laser Scanning, ICERI2008 Conference Programme Edited by International Association of Technology, Education and Development, IATED, Madrid, 2008.

[10] Abrami, P. C., Bures, E. M.: Computer Supported Collaborative Learning And Distance Education, The American Journal of Distance Education, 10 (1996), 37-42.

[11] Salazar, G. et al: The building information model in the civil and environmental engineering education at WPI, ASEE New England Section 2006 Annual Conference.

[12] Gagne, R., et al.: Principles of Instructional Design, $5^{\text {th }}$ ed Thomson Wadsworth, USA, 2005.

[13] Eisenstadt, M., Vincent, T.: The knowledge web: Learning and collaborating on the Net, UK: Kogan Page, 2000.

[14] Salmon, G.: E-tivities: the key to active online learning, London, RoutledgeFalmer, 2002. 